\title{
LA RUTINA COMO IDENTIFICACIÓN FILOSÓFICA-ESTÉTICA ENTRE EL SUJETO OCCIDENTAL Y LATINOAMERICANO ${ }^{1}$
}

\author{
Routine as a philosophical-aesthetic identification between western and \\ Latin-American subject
}

José Pablo Concha*

\begin{abstract}
RESUMEN
Este artículo trata sobre la representación conceptual que configura al "sujeto" occidental; entendemos a este sujeto como aquel que es el resultado de la tradición filosófica europea. Esta conceptualización será confrontada con la filosofía que pretende construir un "sujeto latinoamericano", pero que tensiona su especificidad debido a la dependencia teórica que se manifiesta en la filosofía latinoamericana respecto de la europea. Esta confrontación nos cuestiona la viabilidad del uso de las categorías tradicionales de la filosofía occidental para dar cuenta del sujeto americano, encontrando en la figura de la rutina una estructura sostenedora de cualquier sujeto.

Palabras clave: Sujeto, sujeto latinoamericano, filosofía occidental, filosofía latinoamericana, rutina.
\end{abstract}

\footnotetext{
${ }^{1}$ Este artículo es resultado preliminar del Proyecto Fondecyt $N^{\circ} 1130478$, titulado: La debilidad del "sujeto latinoamericano" como tendencia fuerte en la fotografía documental mexicana, brasileńa y andina, entre 1980 y 2012.

* Instituto de Estética, Pontificia Universidad Católica de Chile. Santiago, Chile. Correo electrónico: jconchal@uc.cl
}

Artículo recibido el 31 de agosto de 2015. Aceptado el 23 de noviembre de 2015. 


\begin{abstract}
This article is about the conceptual representation that configures the western "subject"; we understand this subject as the result of European philosophical tradition. This conceptualization will be confronted with the philosophy that pretends to build a "LatinAmerican subject", but puts tension on its specificity due to the theoretical dependence that's shown in Latin-American philosophy in relation to European philosophy. This confrontation questions us about the viability of using the western traditional philosophical categories for understanding the American subject, finding in the figure of routine a supporting structure of any subject.
\end{abstract}

Keywords: Subject, Latin-American subject, western philosophy, Latin-American philosophy, routine.

\title{
INTRODUCCIÓN
}

Lo que nos preguntamos es sobre la posibilidad de una hermenéutica de la representación del sujeto occidental primero y segundo del sujeto latinoamericano en la filosofía como en la "Teoría latinoamericana" respectivamente y en la producción fotográfica, como lugar de su concreción. Esta pregunta se funda en la dificultad estructural de definir un sujeto a partir de categorías dadas por el pensamiento occidental. Estas muestran su fuerza conceptual en la línea que se traza desde Nietzsche, pasando por Heidegger y llegando a Vattimo, en el intento de situar al "ser" como su fundamento.

Vattimo comienza el segundo capítulo de su libro Más allá del sujeto (1992) aludiendo a la "conocida tesis de Heidegger" en la que este explica metafísicamente la palabra Abendland como "la tierra del ocaso", es decir, interpretando a Occidente como la tierra del ocaso, pero luego agrega que por esta razón es la tierra del ser; o sea, es la tierra del ocaso porque es la tierra del ser. De esta interpretación se vale Vattimo para identificar la figura del declinar como aquella que da sentido al ser. Esta figura luminosa forma parte del logos óptico-lumínico, siendo el resplandor el pasado del ser. Es decir, el ser occidental se funda en una penumbra geográfica. El resplandor se ha desplazado hacia un territorio alejado del que poco se sabe (desde el propio Occidente), dejando en la debilidad existencial al sujeto occidental. ¿Hacia dónde se desplazó el resplandor? ¿Este resplandor, que sería el basamento de un ser fuerte, es el fundamento, entonces, de una metafísica desplazada de su origen? ¿Es posible pensar en una metafísica o una filosofía más allá del territorio del que surgió? ¿Cómo se puede figurar el sujeto que se pone en juego en este desplazamiento, tanto en su territorio original como en aquel que se muestra como destino resplandeciente? 


\section{TENTATIVAS SOBRE EL SUJETO OCCIDENTAL}

Iniciamos nuestra indagación respecto del sujeto a partir de la lectura que hacemos de lo pensado por Gianni Vattimo en el texto antes indicado. Frente a esta interrogación, el filósofo italiano enfrenta una primera aproximación crítica a la figura de "Uebermensch" nietzschiano, aludiendo en primera instancia a la imposibilidad del malentendido o interpretación nazista del asunto, a partir de la subversión de los valores de la tradición "humanista" europea.

La primera proposición que hace el filósofo italiano es que habría "buenas razones" para pensar que el "Uebermensch" sería aquel que es el resultado de la superación dialéctica hegeliano-marxista que toma la forma del "sujeto conciliado". Esta conciliación comprende a los términos "sentido" y "existencia” y sus derivaciones. De este modo, se despeja un primer asunto: no es la subversión valórica sino la conciliación el modo de superación, dada esta por la conciencia de identidad entre "el sentido" y "el evento". Pero, nos dice Vattimo, esta identificación que define al "súper hombre" se funda en la categoría del sujeto, ya que en el plan nietzschiano es el "sujeto" el que es objeto de indagación crítica como contenido de la metafísica y moral cristiana-platónica. Es decir, parte del proyecto nietzschiano ha sido, según Vattimo, "desenmascarar" (p. 28) los contenidos metafísicos y morales de la tradición platónico-cristiana. Así, la posibilidad de comprender el "Ueber" como conciliación en el propio sujeto es crítica. Vattimo se concentra en lo dicho por Nietzsche cuando este indica que no puede pensarse la cosa en sí porque todo se da en su "contexto", por esto, incluso, el sujeto en sí. La imagen crítica del sujeto nietzschiano se debe ver solo como una superficie al que no le es posible volver dialécticamente a un sujeto original y, como consecuencia de esta observación, se verifica un debilitamiento metafísico de este "sujeto". Esta imposibilidad de un sujeto se advierte en la propia dificultad empírica de la dialéctica y el impedimento ontológico de la metafísica. Vattimo se centra, luego, en dos estructuras que Nietzsche advierte han pretendido dar con un "origen" "neurótico" de un "responsable" del acontecer: la causalidad y la estructura del ser que la metafísica ha extraído de ella. La sentencia de Nietzsche es grave: "entretanto, hemos reflexionado mejor. De todo esto no creemos ya una sola palabra" (El ocaso de los ídolos. En Vattimo, 1992). La crítica que se hace desde este lugar a la causalidad es producto de la necesidad -fundamental- de "un responsable" de lo que acontece y Nietzsche observa que el origen de esto es un sentimiento de miedo, en un momento en que la naturaleza todavía se muestra como una fuerza indomable y hostil para la técnica de su tiempo. Esto implica un sentimiento de desamparo que obliga a encontrar al responsable. Asimismo, y siguiendo a Nietzsche, esta determinación causal, finalmente, hace que quien detente un poder particular pueda reconocer al "responsable" de una acción específica y así ejercer 
el poder sobre este sujeto. O sea, la causa del "principio de razón suficiente" es el ejercicio del poder. Así se configuraría una "compleja visión metafísica de la realidad" a través de "mediaciones del dominio social".

La figura del "sujeto" es, en consecuencia, una "metáfora" y una "interpretación” determinadas por las relaciones sociales.

Entonces, si en la filosofía de Nietzsche no se puede hablar de "sujeto" es porque este es producido, por lo tanto ya no sostenido en fundamentos metafísicos. Si no hay sujeto, menos puede haber "sujeto conciliado" y por esta razón no se puede identificar con la figura del Uebermensch.: "...es un juego de palabras, un efecto del lenguaje como es el sujeto mismo", nos dice Vattimo (p. 31). La metafísica es, entonces, una construcción metafórica que produce nociones generalizantes de "cosa" y de "sujeto". "Cosa", en tanto cosa en sí se transforma en ontología. "Sujeto", determinación causal de la responsabilidad moral: ejercicio del poder, a partir de un fundamento.

En este punto de la exposición, Vattimo pone atención en la determinación técnica de la figura del sujeto, en la otra imagen que Nietzsche identifica como "hybris", que resulta equivalente a la explotación a ultranza de la Physis heideggeriana. Esta identificación se funda en la consideración, a partir de esto, del fin de la metafísica: el sujeto solo es en contexto; el sujeto moral es consecuencia del ejercicio del poder (responsabilidad); de aquí se desprende la imposibilidad de sujeto conciliado: fin de la metafísica.Vattimo identifica al sujeto nietzschiano como:

...solo apariencia; pero esta no se define ya como tal en relación a un ser; el término indica solamente que todo darse de algo como algo es perspectiva, que se superpone violentamente a otras, las cuales solo por una necesidad interna de la interpretación son identificados con la cosa misma. En la tesis nietzschiana según la cual voluntad de poder es conferir al devenir los caracteres del ser el acento se pone en el devenir y no en el ser; no se trata de conferir también al devenir, por fin, los caracteres fuertes del ser, sino que es el devenir que deben ser dados, con todo lo que ello comparte, los atributos que antes eran propios del ser (p. 37).

En este punto, entonces, debemos necesariamente pensar, con Heidegger, al ser y de este modo comprenderlo como transición entre Nietzsche y Vattimo.

Ser y Tiempo expone la descripción fenomenológica del Dasein y lo muestra como ente privilegiado para la comprensión del ser. De inmediato, entonces, advertimos que son dos conceptualizaciones de naturaleza diferente, pero vinculadas estrechamente, tanto que una de ellas nos permitiría llegar a la otra.

La existencia y el cuidado son estructuras que sostienen al Dasein y Heidegger las identifica como esencia y como ser respectivamente. Nuevamente, se reconocen dos modalidades de comprensión; una dinámica: el ser como cuidado; y otra estática, la existencia como esencia. 
Precisamente, en el parágrafo 45 de Ser y Tiempo, Heidegger propone una definición de Dasein: "el Dasein es [estático; existencia] en cuanto poder ser comprensor [dinámico; cuidado] al que en tal ser le va este ser como el suyo propio. El ente que es de esta manera lo soy cada vez yo mismo” (p. 251). Esta definición del Dasein es dinámica en tanto se presenta como una posibilidad, por lo tanto puede como no puede "ser"; pero, del mismo modo es estática porque es presentada como el modo privilegiado de ser. Este contraste tiene como telón de fondo la certeza del "yo mismo" como posibilidad absoluta. Es en la posibilidad de reconocerse como un "yo mismo" donde se distingue la característica fundamental de la "comprensión" como determinante del Dasein. O sea, el Dasein es al momento de comprender qué es y esta sería su esencia en tanto existencia. La perspectiva dinámica se da en la actitud de "cuidado" que se expresa en el acontecer fáctico del Dasein como anticipación y proyección. Se completa la posibilidad ontológica de Dasein en la relación entre existencia y cuidado. Esta relación se cumple con la imagen de la "propiedad" y la "impropiedad" que caracteriza la posibilidad de caída en el impersonal "se", siendo la impropiedad el modo eminente de acontecimiento del Dasein.

Esta caracterización nos permite volver a lo señalado por el propio Heidegger al pensar a Occidente como el lugar del ocaso del ser. Si pensamos geográficamente esta formulación, el ser occidental está en la penumbra porque el sol resplandece en el poniente. La luminosidad resplandece en la periferia de Occidente, en el poniente de occidente y geográficamente este lugar es el de Latinoamérica. Esto nos haría aventurar, desde la metáfora, la posibilidad de una ontología fuerte latinoamericana, precisamente, en la constatación vattimoniana de la debilidad ontológica occidental.

Quisiera a esta altura hacer una observación a partir de La hermenéutica del sujeto de Michel Foucault que vale también para lo expuesto hasta aquí. ¿Cuál es el sujeto que se piensa en esta reflexión? Y, además, ¿`ómo piensa ese sujeto que piensa Foucault? Evidentemente, hay tipos diversos de sujetos, en tanto modos de acontecer específicos, pero la filosofía tendría una proyección abarcadora, generalizante del "sujeto" y por esta razón el sujeto que se presenta es "el filósofo" y "el pensar" del filósofo. Esto es lo que se ofrece en esta hermenéutica. Es decir, lo que se trata de conocer como "sujeto" no es el corriente existente heideggeriano, sino el particular sujeto filosófico, ya que, de modo preliminar, Foucault define filosofía como: "la forma de pensamiento que se interroga acerca de lo que permite al sujeto tener acceso a la verdad, la forma de pensamiento que intenta determinar las condiciones y los límites del acceso del sujeto a la verdad” (33). Y más adelante agrega:

La espiritualidad [que es la reunión de las condiciones que hacen posible la reflexión filosófica] postula que la verdad nunca se da al sujeto con pleno derecho. La espiritualidad postula que, en tanto tal, el sujeto no tiene derecho, no goza de 
la capacidad de tener acceso a la verdad. Postula que la verdad no se da al sujeto por un mero acto de conocimiento, que esté fundado y sea legítimo porque él es el sujeto y tiene esta o aquella estructura de tal. Postula que es preciso que el sujeto se modifique, se transforme, se desplace, se convierta, en cierta medida y hasta cierto punto, en distinto de sí mismo para tener derecho al acceso a la verdad. La verdad sólo es dada al sujeto a un precio que pone en juego el ser mismo de éste. Puesto que el sujeto, tal como es, no es capaz de verdad (Ibid).

A partir de esta caracterización del sujeto, es sujeto quien es capaz de modificarse voluntariamente para conducirse a la verdad, asunto crítico cuando el estado del sujeto corriente es la ignorancia de saber que se está fuera de la verdad; por lo demás, ni se lo pregunta. Pero, también se propone como vía para la condición de sujeto un absoluto previo: "la verdad". ¿De qué verdad se habla? ¿Es la verdad en tanto identidad entre sujeto y predicado? ¿Es la verdad como aparición de lo oculto? ¿Es la verdad revelada? En todo caso es una verdad que funda un conocimiento, un saber, una determinación de comprensión particular del sentido, tanto de su propia existencia, como de una proyección teleológica. Esta perspectiva inhabilita y desprecia la experiencia cotidiana que se "pierde" en la rutina. Es como si el individuo rutinario no fuera sujeto y por esto su condición fáctica fuera una ilusión inconsciente. La “cotidianidad mediana” pensada por Heidegger en Ser y Tiempo es, precisamente, el lugar en que acontece el Dasein y es aquí en donde este se pierde. El Dasein, como el acontecer fáctico del ser se pierde en su cotidianidad $y$, nuevamente, es un pensamiento que pretende una autoconciencia más elevada el que es capaz de salirse del curso de la caída al indeterminado "uno" heideggeriano.

Si volvemos atrás y aventuramos una identificación entre sujeto y Dasein, en el marco de la ontología de Heidegger, se exige una condición propia de autointerpretación. En Ontología, hermenéutica de la facticidad (2008) Heidegger interpreta a la hermenéutica desde una perspectiva que expande su sentido más allá de la mera "interpretación" y la ubica en un ámbito material del sentido de la existencia del sujeto; de este modo, el ejercicio hermenéutico no es mera exégesis de los fenómenos, sino que previo a esto es fundamental el cumplimiento de ciertas condiciones de quien interpreta.

La hermenéutica -nos indica Heidegger- tiene la labor de hacer el existir propio de cada momento accesible a su carácter de ser al existir mismo, de comunicárselo, de tratar de aclarar esa alienación de sí mismo de que está afectado el existir. En la Hermenéutica se configura para el existir una posibilidad de llegar a entenderse y de ser ese entender. Ese entender que se origina en la interpretación es algo que no tiene nada que ver con lo que generalmente se llama entender, un modo de conocer otras vidas; no es ningún actuar para con... (intencionalidad), sino un como del existir; fijémoslo ya terminológicamente como el estar despierto del existir para consigo mismo (33). 
Hay que considerar que este texto es anterior y de algún modo preparatorio a lo que será Ser y Tiempo del año 27. Esto es importante porque lo que se interpreta no es algo de orden meramente cultural o natural, sino que es la existencia misma, por esta razón lo fáctico toma vuelo ontológico. Este estar despierto permitirá, según el autor, entender la manera en que se existe; ahora ¿quién es el que existe? Heidegger evita, precisamente, identificar antropológicamente al existente y por esto, asunto que se repite en Ser y Tiempo, utiliza figuras abstractas que mantienen el vuelo generalizante conceptual. Evidentemente, el estar despierto para existir consigo mismo solo lo puede realizar aquel que nosotros reconocemos como sujeto. Este resulta ser todo ser humano, incluso el que se pierde en su mundo cotidiano y rutinario. La figura del sujeto cotidiano no logra una estatura lo suficientemente digna como para ser un lugar de singularidad filosófica, porque es siempre y solo el pensar filosófico el que logra la "conciencia" de su existencia. Podríamos indicar a la responsabilidad de sí en un contexto teleológico como el mecanismo que caracterizaría al sujeto, sea cual sea su acontecer fáctico. Este mecanismo no exige una conciencia particular superior para ser ejercido; todo sujeto busca proveerse de los materiales que le permita existir y por extensión $-\mathrm{y}$ generalmente- la existencia de sus cercanos. El giro a la responsabilidad de sí es hacia la particularidad de los individuos en su rutinaria vida diaria, el sujeto que ejecuta oficios alienantes, como aquel que se autonomiza de la colectividad por oficios de carácter creativos, se despliegan en una serie de hechos corrientes que aseguran su existencia. Este acontecer alienante, Humberto Giannini lo desarrolla en su obra La "reflexión" cotidiana. Hacia una arqueología de la experiencia (2013). El valor que se puede encontrar al espacio rutinario, aun cuando puede ser alienante, es absolutamente fundamental para el justo acontecer individual y social. Sin él no es posible concebir la extensión del sujeto en su propio espacio. Giannini nos dice: “... la rutina consiste en una suerte de absorción de la trascendencia del futuro; absorción de la normalidad de un presente continuo idéntico a sí. Caricatura de eternidad" (p. 47). Esta ausencia de trascendencia significa que no hay posibilidad de desconcierto por lo inesperado, siempre es esperable lo mismo. Esta cualidad de lo rutinario se sostiene, según Giannini, en la estructura que nos entrega la "ruta”; "...la ruta como el camino construido sobre un tramado de normas externas interiorizadas, visibles o invisibles, que aseguran la llegada normal y regular a nuestro destino. Sin embargo, el destino de la rutina se pega [...] a la ruta al mero rodar; se vuelve para vialidad" (p. 46). O sea, la posibilidad teleológica que decíamos más arriba, solo es viable desde la estructura sostenedora de la rutina; sin ella no es dable pensar en alguna trascendencia, ella no es la trascendencia, pero sin ella se abriría un horizonte indeterminado y por esto intrascendente. Por esta razón, la rutina y lo rutinario se presentan como "entramado de normas" (Giannini) que mantendrán al sujeto a salvo de la ambigüedad e incerteza de sus propias percepciones de su acontecer fáctico. 
En la línea de la reivindicación de lo regular, de lo ordinario, respecto del sujeto se encuentra Hanna Arendt. En el parágrafo 38 "El auge de la duda cartesiana" de su obra La condición humana, vuelve a pensar el sentido que esta duda significa para la existencia del ser humano. Las observaciones que la filósofa expone, resitúa el lugar de esta duda, dándole un espacio de singular valor a la incerteza de los datos de la percepción; esto significa que todo aquello que es percibido por los sentidos es susceptible de ser engañoso y falso. Esta evidencia, según Arendt, se hace patente al momento de reconocer la limitación del propio aparato sensible de los individuos frente a la certeza que entregan los aparatos. Por ejemplo, el telescopio, el microscopio, son ortopedias de la percepción; que desde su raíz indica una educación correcta. Es decir, los aparatos ortopédicos serían aquellos que corrigen y educan al soma; en este caso a la percepción visual. Pero, lo que se hace manifiesto es que debido a la certeza de los instrumentos se hace evidente la incerteza del soma. Arendt observa que el valor de la razón científica no es el resultado de la razón humana sino que es gracias a la razón técnica, desde aquí se debe entender la duda cartesiana. Un aspecto interesante de lo dicho por Arendt es que estos sentidos engañosos son guiados por el más elevado de ellos: el sexto sentido. Ese sentido que está presente en todo ser humano, pero que no es en tanto racionalidad lógica, sino que por la comunidad de sentido, es decir, el sentido común que sería el más elevado. Esta consideración es relevante porque lo ubica como determinante en el modo de interpretación del acontecer del individuo. Es decir, llena de humanidad al espacio ordinario del acontecer cotidiano, de acontecer rutinario, como planteábamos más arriba. Este modo de acontecer sostenido colectivamente, es decir, por medio de regulaciones normativas tácitas, de sentido común, expone la pertenencia del sujeto a una trama social normativa que lo antecede y que lo define. Esta normatividad puede registrarse, por ejemplo, en la rutina de la comida diaria (no comer con las manos -en nuestra sociedad-); pero también en acuerdos más complejos, como por ejemplo la censura respecto de matar a un semejante. Esta trama estructural pasa de prácticas sociales simples, hasta determinaciones morales complejas. Arendt sigue a Marcuse y este nos dice que:

La civilización todavía está determinada por la herencia arcaica, y esta herencia, como afirma Freud, incluye 'no sólo disposiciones, sino también contenidos ideológicos, huella en la memoria de las experiencias de generaciones anteriores'. La psicología individual es así, en sí misma, psicología de grupo, en tanto que el individuo mismo todavía tiene una identidad arcaica con las especies (p. 64).

Esta caracterización de la existencia sostenida en lo cotidiano y más aún, en lo rutinario, que además se traspasa en el contexto, es efectivamente otra crítica radical al soporte metafísico del "sujeto" y, por esta razón, complementaria a la observación sartreana de que "la existencia precede a la esencia". El sujeto se "da" 
en su acontecimiento, en su "devenir" en tanto posibilidad de transformación en el transcurso diacrónico de su facticidad. En otro sentido, pero respecto del modo de acontecer descrito por la filosofía sartreana, nos dice el filósofo que:

...el hombre está continuamente fuera de sí mismo; es proyectándose y perdiéndose fuera de sí mismo como hace existir al hombre y, por otra parte, es persiguiendo fines trascendentes como puede existir; el hombre, siendo este rebasamiento mismo y no captando los objetos sino con relación con este rebasamiento. No hay otro universo que este universo humano, el universo de la subjetividad humana (2000, p. 85).

Este "retrato" del hombre en su rebasamiento corresponde a un modo de existir sostenido en su acaecer cotidiano, pero que se proyecta hacia una trascendencia determinada por la materialidad de su despliegue histórico-político.

La descripción que hemos realizado hasta aquí del sujeto es reconocible a partir de la matriz del pensamiento débil vattimoniano cuando este dice que esta filosofía es:

...un procedimiento de corte 'empirista', pero desprovisto de cualquier intento de iniciarse con una cierta experiencia pura o purificada de todo condicionamiento histórico-cultural. La experiencia de la que debemos arrancar, y a la que debemos permanecer fieles, es la de lo que cabría calificar como cotidiano; experiencia que se presenta siempre cualificada desde el punto de vista histórico y preńada de contenido cultural (1995, p. 19).

El pensamiento débil, como "torsión” y "superación” de la dialéctica y la filosofía de la diferencia, identifican a un ser pero ya no uno que se sostiene en estructuras fuertes; por el contrario, la debilidad radica en su materialidad efímera, que tiene a la muerte como horizonte, pero en un trayecto sin proyecto, sin propósito y desprovisto de una verdad trascendente. Esta formulación obliga a pensar de otra manera al sujeto, es como si solo estuviera arrojado a su propia suerte, pero desde una precariedad existencial, es decir, más radical aun que el propio Sartre, ni siquiera hoy hay esencia luego de la existencia, sino pura existencia que debe encontrarse en su acontecimiento material permanentemente, de lo contrario solo es posible la pura devastación. Esta experiencia instala al espacio rutinario como el lugar fundamental, pero desprovisto de intenciones abarcadoras o trascendentes, en el que el sujeto construye, del modo que puede su vida. 


\section{SOBRE EL SUJETO LATINOAMERICANO}

La descripción que acabamos de hacer del sujeto occidental plantea una interrogante fundamental ¿Cuál es el lugar del sujeto latinoamericano en este retrato? ¿Es posible pensar territorialmente la emergencia del ser occidental en la periferia latinoamericana? ¿Puede el latinoamericano ser parte de la tradición del ser occidental? Lo que inmediatamente se advierte es que sí se comparte un lugar: la rutina. Asunto que retomaremos al final de este artículo. La tesis que nos permite continuar con esta segunda parte es la planteada por el sociólogo Jorge Larraín, quien indica que:

El postmodernismo [...] parece permitir al otro cultural su propia voz, el derecho a ser diferente y a no ser subsumido por una lógica universal que elimina la especificidad. [...] Porque pareciera que es la única teoría contemporánea que la da cabida a una voz propia latinoamericana y legitima el derecho latinoamericano a ser diferente (p. 126).

Esta tesis abre una posibilidad de reflexión interesante desde el momento en que ofrece una continuidad entre el espacio céntrico de la postmodernidad y el excéntrico latinoamericano. Esta continuidad regular puede parecer sospechosa al observar la dificultad de identificar relaciones causales entre la periferia y el centro. Esta postmodernidad es la que hemos caracterizado (sabemos que muy parcialmente) en la primera parte de este trabajo, lo que nos muestra que en el fondo de la tesis de Larraín está la aceptación o más aun la subordinación tácita a una tradición que por estar en crisis nos permitiría el despliegue. Este problema fue tratado de modo esclarecedor por Néstor García Canclini en su libro Culturas híbridas del ańo 1990, pero en esta obra no se trabaja de manera particular al sujeto latinoamericano y la posición de esta particularidad en las relaciones sociopolítico-económicas y menos una caracterización existencial.

La pregunta que inevitablemente se debe hacer es ¿Cuál es el sujeto que puede encarnar esta continuidad filosófica desde el centro (expuesto someramente en la primera parte de este artículo y asumido no críticamente como uno trascendente y material y como si fuera homogéneo) a la periferia? ¿Quiénes son aquellos que han sido depositarios de una tradición que ve su origen especialmente en Europa? Una primera aproximación a estas preguntas es la advertencia que indica que no es posible un sujeto homogéneo que dialogue o se enfrente a ese centro que se presenta como hegemónico y especialmente homogéneo. Por de pronto, y como primer acercamiento a elementos caracterizadores del "sujeto latinoamericano", se hace evidente la antinomia campo/ciudad, campesino/ciudadano; campesinado identificado, además, con la originalidad étnica del habitante del espacio rural. 
Ahora bien, quien dialoga con el centro es la elite urbana que verá a Europa como el modelo cultural y político a seguir; asunto verificable en la contemporaneidad cultural. El espacio campesino e indígena se diferencia de este otro sujeto debido a su contexto educativo y cultural. La precariedad material de la educación ralentiza la incorporación de estos sujetos a una contemporaneidad técnica urbana homogenizante globalmente. Por esta razón, la tesis de Larraín debe ser vista con cuidado. La globalización técnica homogenizante distribuye contenidos descontextualizados y el riesgo es que quienes acceden a ellos lo hacen desde la dificultad de la decodificación contextual y de este modo el "sentido" será situado en relación a su propio acontecer histórico. Esta ubicación implica tres posibles miradas críticas: en primer lugar, la posibilidad de "contaminación”. Lo que supone una originalidad virginal de sujetos específicos y, por esto, el deber de ser mantenidos "incontaminados". En segundo lugar, y a partir de la anterior, el "sujeto" originario debe su sentido trascendental a esta originariedad, pero además a su incapacidad de defenderse de la potencia ideológica técnica; es decir, sería un sujeto igualmente débil. Y tercero, como consecuencia de la segunda, el sujeto originario "debe" ser resguardado, asunto determinado por la jerarquía colonizadora, con rasgos de compromiso ético. Esta relación de fuerzas las caracteriza Eduardo Galeano en las primeras líneas de su libro Las venas abiertas de América Latina del año 1971, como un territorio que desde la colonización se "especializó" en servir y abastecer a los europeos y por esta razón, e inevitablemente, desde una posición de subordinación económica, cultural y espiritual; como mera herramienta que desaparece en el uso.

El problema del sujeto puede tener dos vías de análisis, por un lado, la identificación de una "filosofía latinoamericana" que lo trata y desde aquí establecer "fluidamente" el diálogo con la filosofía continental; por otro, el problema de la "identidad latinoamericana" desde un ámbito más bien sociológico, y desde aquí como contraparte original respecto del centro; por ejemplo, lo realizado por Jorge Larraín o el propio Galeano.

Desde la filosofía, el interesante libro de José Santos-Herceg Conflicto de las representaciones. América Latina como lugar para la filosofía editado por el Fondo de Cultura Económica en año 2010, aborda en su segunda parte las proposiciones de diversos intelectuales latinoamericanos en relación a la posibilidad de filosofar y de la figura del filósofo. Una primera afirmación es que efectivamente "nuestro espacio" es heredero de manera indiscutible de la cultura europea, pero el autor, citando a Nelly Richard, caracteriza esta herencia como nuestro "trauma de la marca colonizadora". Es decir, ha sido una actitud militante de nuestra reflexión esforzarse en borrar una parte fundamental del origen y tratar de producir una voz original. La pregunta que se debe realizar ahora es ¿por qué esta insistencia en borrar? Tal vez el trauma no es el asunto de la colonización, sino más bien la del hijo no reconocido que espera que el padre lo valide como un igual. Este parece más 
un problema de orden psicoanalítico que de un asunto filosófico. Santos-Herceg citando a Enrique Molina afirma que la filosofía latinoamericana tiene la facultad de uso de la filosofía occidental, precisamente por ser heredera de esta tradición.

Santos-Herceg advierte que algunas de las filosofías latinoamericanas apuntan a un localismo arraigado en la tierra, en una filosofía localizada del Manifiesto salteño, o, el pensamiento religado de Pedro Trigo, donde lo determinante es el contexto violento de la historia de esta tierra. Estos esfuerzos por identificar una filosofía propiamente latinoamericana tienen como trazo común la voluntad de emancipación del pensamiento europeo, tratando de reconocer algún aspecto trascendental del territorio para constituirse en un fundamento ontológico. Lo que nos queda resonando en la necesidad de una "ontología latinoamericana”, siendo esta fórmula ya propiamente occidental y por esto no ajustable plenamente a la experiencia filosófica latinoamericana.

Respecto de la caracterización del sujeto en Santos-Herceg, el autor retoma una figura que ha sido frecuentemente abordada por distintos filósofos latinoamericanos, la de Calibán. Leopoldo Zea fue uno de los primeros en proponer esta figura como una manera eficiente de pensar al sujeto latinoamericano, como aquel que adopta un lenguaje extrańo, pero que no piensa como quien le dio ese lenguaje. Pero Santos-Herceg cae en un vicio clásico del pensamiento filosófico y es encarnar la reflexión de la identidad latinoamericana en la figura del filósofo; esta es la misma crítica que esbozábamos más arriba en relación a lo dicho por Foucault. Santos-Herceg indica que:

Tres de ellos [se refiere a los personajes de La Tempestad] han servido para dibujar una serie de arquetipos de filósofos (la cursiva es nuestra), aunque sin duda el análisis podría ser incluso más fructífero. [...] El filósofo/Próspero es, en cuanto que filósofo europeo, tanto el pensador del poder, del dominio, como el de la liberación. El filósofo/Ariel, por su parte, es tanto el pensador libre como esclavo, dicho más correctamente, es esclavo en tanto que libre, etéreo, desvinculado de su mundo, de su contexto (p. 276).

Más allá del rendimiento filosófico que se le pueda dar a esta reflexión, lo que nos inquieta es la identificación que se hace entre el sujeto filosófico y el sujeto en general, siendo esta una práctica recurrente en el pensamiento de matriz filosófica. El "sujeto" obedece a una trama tejida por diversos flujos culturales y experienciales en el contexto de su propia cotidianeidad que hace imposible esta identificación que es puramente conceptual. Por esta razón, es interesante como Gabriel Castillo (2003), usando la misma metáfora trabajada por Zea y por SantosHerceg, no cae en la tentación de hacer esta identificación y despeja la relación entre el personaje de Shakespeare y un sujeto abierto: 
El sujeto americano ha girado en torno a un objeto nocturno forjándose una conciencia de la contradicción entre la marginalidad y la heterogeneidad de su existencia y la centralidad y homogeneidad del episteme que lo nombra. La estrategia estética de la filosofía nocturna nace de la incertidumbre respecto del derecho a hablar en la lengua del colonizador y encarna una primera tentativa de pensamiento de descolonización. La condición negativa de una identidad americana, como margen, revela también el hecho de que ni Europa ni América son sistemas homogéneos, uno moderno, el otro no moderno o pre-moderno, sino más bien un solo sistema heterogéneo dentro del cual la función marginal del mundo americano pone en evidencia la fragilidad del Occidente como único origen posible de sentido (p. 191).

Entenderé aquí por "objeto nocturno" al modo de simbolización por medio de objetos sospechosos para significar la "trascendencia". Digo trascendencia en el más estricto sentido materialista y nunca metafísico; esto quiere decir que la existencia se da en la finitud de los acontecimientos, pero en la extensión del "sentido". Ahora bien, este sentido no pretende ser una teleología, sino que, por el contrario, una significación del acontecimiento inmediato dado en la obra simbólica. La condición sospechosa se debe a que no corresponde a los objetos que la cultura tradicional ha consagrado como portadores privilegiados de la belleza o del espíritu; por el contrario, son aquellos que desde esta territorialidad atomizada encarnan una significación identitaria. Ya no será Occidente el referente de significación, sino la encarnación de ese primer gesto de autonomía de sentido.

La idea de la imposibilidad de definición y caracterización del sujeto latinoamericano evidencia la fundamental diferencia con el centro hegemónico y es que este se pensó durante toda la modernidad desde una homogeneidad inexistente, y por esta razón la filosofía latinoamericana se ha visto atrapada en la búsqueda de una homogeneidad equivalente, pero que, en rigor y del mismo modo, nunca ha existido. El español, el criollo, el negro y el natural y todas las hibridaciones posibles (para usar el concepto acuñado por García Canclini), construyen una heterogeneidad inclasificable. Ni siquiera por el uso de una misma lengua. A pesar de lo dicho por Tugendhat (2004), cuando plantea que la comunidad de hablantes se constituye como tal cuando se usa el mismo lenguaje y que todos entienden lo mismo de las mismas palabras. Es evidente que nuestra lengua americana es de matriz española, pero es igualmente evidente que la diversidad material latinoamericana impone sistemas de denominaciones lingüísticas igualmente distintas. En este sentido, Antonio Campillo plantea que, refiriéndose al sujeto:

Es una invención política, porque no consiste en una objetividad naturalmente dada, que se recibe al nacer y se posee de una vez por todas, sino que consiste en una subjetividad históricamente modelada, que se adquiere en la convivencia con los otros y experimenta toda clase de transformaciones"(2001, p. 219). 
La calidad política de la "sustancia" del sujeto es en estricto rigor lo dado en la relación con los sujetos próximos que identifican modos comunes de desplegarse en su "paisaje". Este paisaje es uno de los resultados del lenguaje en común que determina identificaciones particulares a realidades específicas propias de una comunidad. La comunidad construye una identidad a partir de los sujetos que la constituyen, que a su vez son modelaciones políticas.

Campillo identifica algunas paradojas que se manifiestan cuando tratamos de pensar en el "sujeto", en la primera observa que:

...la entidad a la que consideramos persona y a la que identificamos con un nombre propio es a la vez, inseparablemente, un objeto físico y un sujeto político, un organismo vivo y un agente moral, un algo de lo que hablamos y un alguien con quien hablamos, una 'cosa' a la que podemos conocer, describir y manipular, y una 'persona' a la que podemos reconocer, prescribir y respetar (Ibid, p. 220).

La dualidad que se expone en este fragmento caracteriza a un sujeto que está tensionado por diversos contextos que otorgan sentidos diversos a su devenir, es decir, es vano tratar de configurar una identidad fija, y por esto identificable a una figura como la del "sujeto latinoamericano".

Leonor Arfuch describe el asunto de la Identidad latinoamericana como un problema de orden académico que aparece en la década de los 80 y que permite la aparición y

el afloramiento de identificaciones éticas, regionales, lingüísticas religiosas, a veces en retorno a anclajes ancestrales, a formas previas a la delimitación modernas de los estados-nación, amenazadas de cristalización fundamentalista o en busca de una mayor autonomía, se articulaba a otro relato multiplicador en el sitio paradigmático de las grandes ciudades: el de las minorías, grupalidades y diferencias, cuyo rasgo distintivo era la creciente capacidad de elección, su afirmación constitutiva en tanto diferencias. Identidades políticas no tradicionales, nuevas formas de ciudadanía, identificaciones etarias, culturales, sexuales, de género, emergían con sus demandas en el espacio urbano y mediático, en pugna por derechos y reconocimientos (p. 21).

Arfuch nos presenta una descripción identitaria sostenida en la inexistente necesidad de cristalizar caracterizaciones rígidas y limitantes de los sujetos que se configuran bajo la denominación de "Latinoamericanos". Esta apertura es la verificación de una diversidad inclasificable que podría inestabilizar la pretendida identidad homogénea. El reconocimiento de estas identidades particulares podría tener consecuencias políticas significativas, debido a la aparición de demandas sociales inesperadas en una sociedad más bien conservadora. Por esta razón sería 
más eficiente para un Estado la homogeneidad "nacional" de sus miembros que la heterogeneidad, no advirtiendo en la diversidad la construcción de tramas culturales fértiles.

Aquí, entonces, es necesario retomar un concepto que permite identificar un ámbito en que todo sujeto se iguala con otro: la rutina. Esta es todo aquello que se debe hacer casi de modo inconsciente o inadvertidamente para poder fundamentar la existencia. Todo sujeto debe sostenerse en la rutina. Podríamos reconocer que existen dos tipos de rutina, una pública y otra privada. Esta, se identifica con lo doméstico; aquélla, con el desenvolvimiento social. En este se consiguen los materiales para la provisión de los alimentos; en lo doméstico se cocinan, por ejemplo. El desplazamiento hacia el trabajo (en lo público) obliga a realizar una serie de acciones inconscientes "rutinarias" como caminar al transporte público o manejar para llegar al trabajo; en lo privado doméstico, ducharse, vestirse, desayunar para luego salir. Acciones que permitirán trabajar y así obtener los alimentos. Sin estas rutinas estaríamos siempre en lo extraordinario, lo que nos impediría un desenvolvimiento social coherente. $\mathrm{O}$ sea, la rutina es un fundamento. Cada sujeto define sus propias rutinas, sus propias estructuras sostenedoras que le permiten ser parte de una sociedad y de este modo satisfacer sus necesidades para poder vivir. La rutina no ha sido objeto frecuente de valoración filosófica o histórica como sostenedora de la existencia, pero sí los grandes relatos particularmente políticos; estos han sido los que configuran la existencia, pero desde una perspectiva "extraordinaria". De esta manera, podemos reconocer un fundamento estético común a todo sujeto: su propio acaecer rutinario. El sentido estético de la rutina lo identificamos en el encuentro cotidiano de nuestros sentidos con las cosas que nos rodean. La configuración espacial de nuestro entorno inmediato -como espacio rutinario interior- $\mathrm{y}$ del espacio rutinario público tiende a desaparecer en la experiencia y devaluado en su importancia, pero es la manifestación próxima de nuestra propia condición estética. De este modo, se puede entender el giro íntimo que han experimentado algunas manifestaciones artísticas, tanto en el centro como en la periferia occidental.

La rutina tiene alcances casi metafísicos cuando Humberto Giannini la caracteriza como "caricatura de eternidad" (2013: 47). Esta fórmula puede tener cierto aroma despectivo, pero si atendemos a la reflexión sobre el tiempo en la rutina que el propio Giannini expone, llegamos a que la rutina es la posibilidad de una temporalidad fuera de la diacronía. Giannini nos dice: “...una existencia rutinaria es tal en cuanto no se abisma en los abismos del tiempo, en cuanto nivela todas sus dimensiones y simplemente es lo que viene de ser (donde pasar y pasado se confunden), y espera ser lo que proyecta en un futuro sin distancia” (47). 


\section{REFERENCIAS}

Arendt, Hanna. La condición humana. Buenos Aires: Paidós, 2012.

Arfuch, Leonor (comp.). Identidades, sujeto y subjetividades. Buenos Aires: Prometeo, 2005.

Campillo, Antonio. La invención del sujeto. Madrid: Biblioteca Nueva, 2001.

Castillo, Gabriel. Las estéticas nocturnas. Santiago, Chile: Instituto de Estética Pontificia Universidad Católica, 2003.

Foucault, Michel. La hermenéutica del sujeto. México: Fondo de Cultura Económica, 2011.

Galeano, Eduardo. Las venas abiertas de América Latina. Santiago, Chile: Pehuén, 2006.

García Canclini, Néstor. Culturas híbridas. Buenos Aires: Paidós, 2010.

Heidegger, Martin. Ser y Tiempo. Santiago, Chile: Ed. Universitaria, 1997.

Heidegger, Martin. Ontología, hermenéutica de la facticidad. Madrid: Alianza Editorial, 2008.

Larraín, Jorge. ¿América Latina moderna? Santiago, Chile: LOM, 2011.

Nietzsche, Frederich. El ocaso de los ídolos. Milán: Ed Colli. Montinari, 1975.

Santos-Herceg, José. Conflicto de las representaciones. América Latina como lugar para la filosofía. Santiago, Chile: Fondo de Cultura Económica, 2010.

Sartre, Jean Paul. El existencialismo es un humanismo. Barcelona: Edhasa, 2000.

Vattimo, Gianni. Más allá del sujeto. México: Fondo de Cultura Económica, 1992. 